\title{
Controle de nematóides parasitos gastrintestinais por Arthrobotrys musiformis em ovinos naturalmente infestados mantidos em pastagens
}

\author{
Érika Barbosa Neves Graminha( ${ }^{(1)}$, Antonio Carlos Monteiro( ${ }^{(1)}$, Heloísa Cristina da Silva ${ }^{(2)}$, \\ Gilson Pereira Oliveira(2) e Alvimar José da Costa(3)
}

\begin{abstract}
(1)Universidade Estadual Paulista (Unesp), Faculdade de Ciências Agrárias e Veterinárias (FCAV), Dep. de Produção Vegetal, Via de Acesso Prof. Paulo Donato Castellane, s/no, CEP 14884-900 Jaboticabal, SP. E-mail: kagrami@hotmail.com, montecar@fcav.unesp.br (2)Unesp, FCAV, Centro de Pesquisas em Sanidade Animal (CPPAR). E-mail: helocsilva@hotmail.com, gilsongpod@hotmail.com (3)Unesp, FCAV, Dep. de Patologia Veterinária, CPPAR. E-mail: cppar@asbyte.com.br
\end{abstract}

\begin{abstract}
Resumo - Este trabalho objetivou avaliar, in vitro e in vivo, o fungo predador Arthrobotrys musiformis, administrado via oral na forma de conídios microencapsulados em alginato ou in natura em meio líquido, após passagem pelo trato gastrintestinal de ovinos. No teste in vitro, avaliou-se a manutenção da atividade predatória, e no teste in vivo, a capacidade de controlar nematóides parasitos de ovinos naturalmente infectados, mantidos em pastagens. O resultado do teste in vitro confirmou a viabilidade de $A$. musiformis (95,5\%), mesmo após a passagem pelo trato gastrintestinal. Na avaliação in vivo, não houve diferença estatística entre o número de ovos por grama de fezes dos grupos tratados e controle, provavelmente em razão da baixa lotação dos piquetes, da quantidade e periodicidade insuficientes de oferecimento de conídios aos ovinos, o que teria proporcionado dispersão e migração das larvas na pastagem. Contudo, os helmintos recuperados na necropsia dos animais traçadores mostraram que A. musiformis reduziu em 50,9\% e 57,6\% o número de Trichostrongylus colubriformis dos grupos tratados com conídios microencapsulados e in natura, respectivamente, e em 95\% o número de L4 de Haemonchus do grupo tratado com conídios in natura. Embora os resultados não sejam conclusivos, A. musiformis mostrouse promissor agente no biocontrole de nematóides parasitos gastrintestinais.
\end{abstract}

Termos para indexação: controle biológico, fungos nematófagos, fungos predadores.

\section{Control of gastrintestinal parasitic nematodes by Arthrobotrys musiformis in naturally infested sheep maintained on pastures}

\begin{abstract}
The objective of the present study was to assess in vitro and in vivo the predatory fungus Arthrobotrys musiformis administered orally, in the form of alginate-microencapsulated conidia, or in natura in liquid medium after passage through the gastrointestinal tract of sheep. Maintenance of the predatory activity of the fungus was evaluated in the in vitro test, and its ability to control parasitic nematodes in naturally infested sheep maintained on pastures was analyzed in the in vivo test. The result of the in vitro test confirmed the viability of A. musiformis (95.5\%) even after passage through the gastrointestinal tract. In vivo analysis revealed no difference in the number of eggs per gram between treated and control groups, probably because of the low crowding of the corrals, the insufficient amount and interval time of conidial supplying, permitting dispersal and migration of the larvae in the pasture. However, helminths recovered at autopsy from the tracer animals showed that A. musiformis reduced $50.9 \%$ and $57.6 \%$ the number of Trichostrongylus colubriformis in the groups treated with microencapsulated conidia and conidia in natura, respectively, and 95\% the number of L4 larvae of Haemonchus in the group treated with conidia in natura. Despite the inconclusiveness of the results, A. musiformis was considered a promising agent in the biocontrol of gastrintestinal parasitic nematodes.
\end{abstract}

Index terms: biological control, nematophagous fungi, predacious fungi.

\section{Introdução}

A utilização de agentes biológicos com atuação sobre ovos e larvas de nematóides trichostrongilídeos, como alternativa para higienização das pastagens, tem sido intensificada nos últimos anos. Os fungos nematófagos são os microrganismos mais estudados com este objetivo.
Esses fungos vivem na matéria orgânica do solo, onde desenvolveram relações parasíticas ou predatórias com os nematóides, e são classificados como ovicidas, endoparasitas e predadores (Barron, 1977).

A forma mais prática de se fornecer esses fungos aos animais é pela administração oral (Araújo et al., 1999). Após passar pelo trato gastrintestinal e ser 
eliminado com as fezes no meio ambiente, o fungo coloniza o bolo fecal, estabelece contato com as larvas eclodidas, produz armadilhas e as leva à morte.

A resistência à passagem pelo trato gastrintestinal é uma característica importante em fungos nematófagos, quando se tem em vista a possibilidade de desenvolver formulações de uso oral que permitam o controle biológico.

Ao analisarem uma formulação do fungo Monacrosporium thaumasium, isoladamente e associada estrategicamente com ivermectina, no controle de nematóides gastrintestinais parasitos de bovinos, Araújo et al. (2004) verificaram que ambos os tratamentos reduziram significativamente o número de ovos por grama de fezes (OPG), quando comparados à testemunha e ao tratamento apenas com o quimioterápico, e reduziram o número de larvas infectantes na pastagem.

Araújo et al. (1998) testaram a viabilidade de um isolado de Arthrobotrys robusta em nematóides parasitos de bovinos. Os animais foram tratados com dois milhões de conídios, duas vezes por semana, durante quatro meses, tendo sido observada uma redução de $73,81 \%$ no OPG, e 70,45\% no número de vermes recuperados da necropsia dos animais, nos últimos três meses de experimento.

Larsen et al. (1991) simularam, em laboratório, as condições do trato gastrintestinal dos ruminantes, para avaliar a sobrevivência de fungos após passagem. Entre as espécies selecionadas, duas do gênero Arthrobotrys e seis de Duddingtonia conseguiram reduzir o número de larvas de Ostertagia ostertagi em valores que variaram de $76 \%$ a $99 \%$, tendo-se obtido considerável eficiência.

Fungos predadores têm sido estudados como alternativa aos produtos químicos sintéticos usados no controle de helmintos parasitos gastrintestinais de ruminantes; é necessário selecionar linhagens que tenham potencialidade para serem usadas no biocontrole desses parasitos.

O objetivo deste trabalho foi avaliar, in vitro e in vivo, o fungo Arthrobotrys musiformis, administrado nas formas microencapsulado e in natura, após passagem pelo trato gastrintestinal de ovinos.

\section{Material e Métodos}

\section{Avaliação in vitro}

Nesse ensaio, utilizou-se um isolado do fungo predador de nematóides $A$. musiformis, que comprovadamente tem a capacidade de passar pelo trato gastrintestinal de ovinos (Graminha et al., 2005).

$\mathrm{O}$ fungo foi cultivado à temperatura ambiente, em placas de Petri com ágar-água a 2\% p/v (AA) (20 g de ágar dissolvidos em $1.000 \mathrm{~mL}$ de água destilada). Para estimular a predação, o parasitismo e, conseqüentemente, a produção de conídios, realizaram-se adições freqüentes de $1 \mathrm{~mL}$ de suspensões de Panagrellus sp. com cerca de $1 \times 10^{3}$ larvas $\mathrm{mL}^{-1}$. Os conídios foram retirados das placas com espátula de Drigalsky, por meio de lavagem com $1 \mathrm{~mL}$ de água destilada esterilizada. Após quantificação, fez-se diluição apropriada para obtenção da concentração a ser avaliada. Uma parte da suspensão obtida foi usada para fornecer os conídios in natura aos animais e a outra parte para o preparo dos conídios microencapsulados.

Foram pesadas, individualmente, 16 amostras de $2 \mathrm{~g}$ de fezes de ovinos positivas para ovos de estrongilídeos, por meio da técnica de Gordon \& Whitlock (1939), com cerca de 8.000 ovos g-1 $^{-1}$, e foram formados dois grupos. O primeiro grupo constou de oito amostras sem adição de conídios e o segundo de oito amostras com adição de $2 \times 10^{5}$ conídios de A. musiformis $\mathrm{g}^{-1}$ de fezes.

Após a adição de conídios, as fezes foram homogeneizadas individualmente, acrescentando-se vermiculita (2:1) e, em seguida, incubadas à temperatura de $25^{\circ} \mathrm{C}$, durante sete dias. Após esse período, as larvas infectantes foram extraídas pelo método de Baermann e quantificadas (Chandrawathani et al., 1998). A identificação das larvas foi realizada segundo os critérios morfológicos preconizados por Keith (1953).

Com base nos resultados das contagens de larvas presentes nas coproculturas dos grupos experimentais, calculou-se a eficácia de predação, por meio da seguinte fórmula:

Porcentual de eficácia $=100$ [(Média do número de larvas do grupo controle - Média do número de larvas do grupo tratado)/Média do número de larvas do grupo controle)].

\section{Preparação dos conídios microencapsulados}

Em recipiente com $700 \mathrm{~mL}$ de água destilada, adicionaram-se $20 \mathrm{~g}$ de alginato de sódio, gradativamente, sob agitação, até completa hidratação e, a seguir, 2 g de benzoato de sódio, como agente bacteriostático. Em outro recipiente com $150 \mathrm{~mL}$ de água destilada, colocou-se $0,25 \mathrm{~g}$ de polisorbato 80 , mais $20 \mathrm{~g}$ de farinha de aveia. Foram acrescentados à essa mistura o alginato de sódio e o benzoato. À mucilagem formada, adicionou-se água 
destilada até completar o volume de $1.000 \mathrm{~mL}$, considerando-se o volume da suspensão de conídios a ser adicionada. A seguir, acrescentou-se suspensão de conídios de modo a fornecer, a cada animal, semanalmente, $2 \times 10^{6}$ conídios do fungo.

A mucilagem, sob constante agitação, foi transferida para um funil de separação, e gotejada em $1.000 \mathrm{~mL}$ de solução de cloreto de cálcio, que também permaneceu sob agitação durante todo o procedimento (adaptado de Fravel et al., 1985). Os microgrânulos obtidos foram recolhidos em peneira, lavados com água destilada e transferidos para peneira plana, onde foram secados por meio de ventilação forçada, em temperatura ambiente.

\section{Avaliação in vivo}

A avaliação da capacidade do isolado de A. musiformis em realizar o controle biológico in vivo foi realizada na Fazenda Santa Irene, Município de Jaboticabal, SP, no período de janeiro a junho de 2004.

Vinte e sete ovinos machos, mestiços, com idade entre seis e doze meses, naturalmente infestados por nematóides parasitos, foram distribuídos aleatoriamente em três piquetes com Tifton (Cynodon dactylon), com taxa de lotação igual a $1 \mathrm{UA} \mathrm{ha}^{-1}$, para a formação dos grupos experimentais: animais que não receberam o fungo (Grupo A); animais que receberam, semanalmente, $2 \times 10^{6}$ conídios microencapsulados de $A$. musiformis por animal (Grupo B); animais que receberam, semanalmente, $2 \times 10^{6}$ conídios in natura de A. musiformis por animal (Grupo C).

A cada 14 dias, durante 120 dias, foram colhidas amostras de fezes diretamente do reto de cada animal. Dessas amostras fecais, efetuou-se a contagem de ovos (OPG), segundo técnica descrita por Gordon \& Whitlock (1939).

Foram realizadas coproculturas das amostras, segundo método preconizado por Robert \& O’Sullivan (1950): $20 \mathrm{~g}$ de fezes dos animais, retirados diretamente do reto, foram misturados com vermiculita (2:1), umedecidos e levados a estufa a $25^{\circ} \mathrm{C}$, durante sete dias, para a obtenção de larvas infectantes dos nematóides parasitos. As larvas foram identificadas de acordo com os critérios recomendados por Keith (1953).

Amostras de $400 \mathrm{~g}$ da massa foliar da pastagem foram colhidas de cada piquete para recuperação do terceiro estágio larvar. As amostras foram acondicionadas em baldes de plástico, com capacidade para $10 \mathrm{~L}$, preenchidos com água à temperatura de $37^{\circ} \mathrm{C}$, e permaneceram em repouso por três horas para liberação das larvas.
Em seguida, retirou-se a massa foliar e os baldes foram colocados na geladeira, à temperatura de $10^{\circ} \mathrm{C}$, por seis horas, para a sedimentação larvar. O sobrenadante foi sifonado, coando-se o precipitado em tamis de $200 \mu$ m para posterior decantação em copo de Hoffman. O sedimento foi examinado em microscópio óptico, e as larvas quantificadas e identificadas segundo Keith (1953).

Nos dois últimos meses do experimento, dois animais traçadores foram introduzidos por grupo de tratamento, a fim de medir a contaminação da pastagem por nematóides. Esses ovinos, antes de serem inseridos nos piquetes, foram desverminados com fosfato de levamizol ( $1 \mathrm{~mL} 40 \mathrm{~kg}^{-1}$ de peso vivo), uma vez por semana, por 21 dias, e mantidos em boxe ripado até o décimo dia após o último tratamento. Os animais permaneceram por 20 dias nas pastagens, sendo, então, retirados e estabulados por mais sete dias até a necropsia.

O sistema digestivo foi separado, por meio de ligaduras duplas, em diferentes segmentos anatômicos (abomaso, intestino delgado e intestino grosso).

Do conteúdo total de cada segmento, retirou-se uma alíquota de 10\% (após homogeneização) para exame e estimativa da carga parasitária (helmintos). Os órgãos esplênicos também foram examinados, para averiguação in totum dos helmintos eventualmente presentes. Todo o conteúdo e raspado, de cada segmento, foi tamisado e a parte sólida fixada em formol a $10 \%$, aquecido a $80^{\circ} \mathrm{C}$.

A colheita, contagem e identificação genérica dos parasitos, presentes em cada alíquota, foram efetuadas em estereomicroscópio. O diagnóstico específico foi realizado por meio de microscopia ótica (Levine, 1968; Costa, 1982).

Dados meteorológicos relativos ao período experimental foram colhidos no acervo da área de Agrometeorologia, do Departamento de Ciências Exatas da FCAV/Unesp. Esses dados se referem às médias mensais da temperatura média com amplitude de variação, umidade relativa do ar e precipitação pluvial (Figura 1).

\section{Análise estatística}

No ensaio in vitro, o delineamento experimental foi o inteiramente casualizado, composto por dois grupos e oito repetições cada. Na análise de variância dos dados obtidos, utilizou-se a transformação $\log (x+5)$, preconizada por Little \& Hills (1978). As análises foram realizadas com aplicação do teste $\mathrm{F}$ a $1 \%$ de probabilidade. Nas análises dos resultados de OPG, utilizou-se um deli- 
neamento em parcela subdividida no tempo (Split Plot in Time), considerando-se os grupos tratados e controle (nove repetições cada) como tratamento principal, e como tratamento secundário as datas de observações (Banzatto \& Kronka, 1989). Os dados foram transformados em $\log (\mathrm{x}+1)$, e as médias comparadas pelo teste de Tukey a 5\% de probabilidade. Para a execução das análises, utilizou-se o programa SAS (1996).

\section{Resultados e Discussão}

Os resultados do teste in vitro (Tabela 1) demonstraram que o fungo $A$. musiformis foi eficaz (95,5\%), mesmo após passagem pelo trato gastrintestinal dos ovinos, não tendo sofrido, portanto, alteração quanto à capacidade predatória para larvas de nematóides parasitos de ovinos.

Melo et al. (2003) constataram a atividade predatória in vitro de Monacrosporium thaumasium (79,24\%) sobre Haemonchus contortus, após passagem pelo trato gastrintestinal de caprinos, ao passo que Waller et al. (1994) mostraram que conídios de Arthrobotrys oligospora, A. oviformis e Geniculifera eudermata sobreviveram à passagem pelo trato gastrintestinal de ovinos in vitro.

Os resultados quinzenais dos exames de OPG dos grupos de ovinos controle (A) e tratados (B e C) estão apresentados na Figura 2.

A utilização de fungos nematófagos no controle biológico de parasitos gastrintestinais visa a promover a diminuição de larvas nas pastagens. Considerando-se

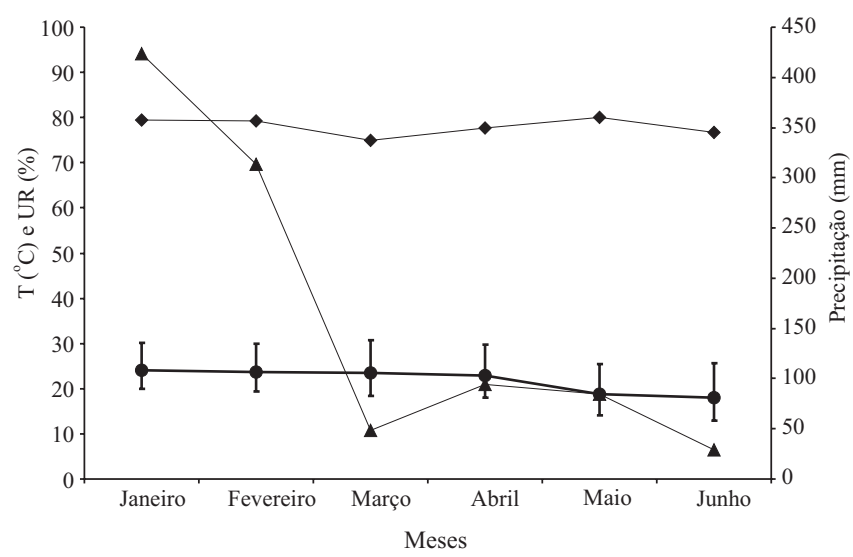

Figura 1. Médias mensais da temperatura média (•) e amplitude de variação (máximas e mínimas), da umidade relativa do ar $(\boldsymbol{\vee})$ e da precipitação pluvial ( $\mathbf{\Delta}$ ) em Jaboticabal, SP, no período de janeiro a junho de 2004. que os conídios microencapsulados ou in natura fornecidos aos animais, via oral, são eliminados nas fezes do ovino junto com os ovos do parasita, esperava-se que, com a eclosão, as larvas fossem predadas pelo fungo e tivessem sua sobrevivência reduzida nas pastagens. Isso acarretaria em menor reinfecção dos animais, e provavelmente, reduziria o OPG nas defecações seguintes. Porém, os resultados não confirmaram essa tendência, pois o OPG dos grupos tratados foi superior ao do placebo. É possível que a baixa taxa de lotação de animais no pasto, a quantidade de conídios fornecidos aos animais e a periodicidade do fornecimento tenham sido insuficientes para permitir boa dispersão do fungo na pastagem, tendo dificultado a predação de larvas infectantes, o que, provavelmente, proporcionou a reinfestação dos animais e resultou na não-redução do OPG.

A taxa de lotação pode ser expressa em UA (unidade animal); 1 UA corresponde a um bovino adulto com $450 \mathrm{~kg}$ de peso vivo, e uma ovelha adulta equivale a 0,2 UA (Susin, 1996). Neste trabalho foi utilizada a taxa de lotação igual a $1 \mathrm{UA} \mathrm{ha}^{-1}$, de modo a proporcionar oferta adequada de forragem aos animais, por todo o período do experimento, sem a necessidade de qualquer tipo de suplementação volumosa.

Segundo Ciordia et al. (1971), citado por Araújo (1996), bovinos que pastam em taxas de lotação de pastagem baixas, não ingerem material próximo ao solo, e evitam, portanto, o consumo de matéria seca à altura onde portam as larvas de 3 o estádio, o que poderia dimi-

Tabela 1. Larvas L3 de Haemonchus, Trichostrongylus, Cooperia e Strongyloides recuperadas das culturas das amostras de fezes tratadas com conídios de Arthrobotrys musiformis, após passagem pelo trato gastrintestinal de ovinos, com oito repetições ${ }^{(1)}$.

\begin{tabular}{ccc}
\hline Repetição & A. musiformis & Controle \\
\hline 1 & 128 & 852 \\
2 & 123 & 2.452 \\
3 & 93 & 3.570 \\
4 & 112 & 2.532 \\
5 & 23 & 1.878 \\
6 & 70 & 3.818 \\
7 & 235 & 2.847 \\
8 & 120 & 2.240 \\
\hline Total & 904 & 20.189 \\
Média & $113 \mathrm{~B}$ & $2.524 \mathrm{~A}$ \\
Desvio-padrão & 60,48 & 938,97 \\
Eficácia (\%) & 95,52 & - \\
\hline
\end{tabular}

(1)Valores originais expressos em médias aritméticas, mas análise estatística realizada com médias transformadas em $\log (x+5)$; médias seguidas de letras maiúsculas distintas, na linha, diferem entre si pelo teste de Tukey a 5\% de probabilidade. 
nuir a chance de infecção desses animais, em relação àqueles que pastam em taxas de lotação maiores. Além desse fator, nos meses de janeiro e fevereiro, ocorreram chuvas torrenciais que favoreceram a permanência de alta umidade relativa no ambiente, provavelmente dificultando o acesso de larvas às pastagens (Figura 1).

Segundo Amarante \& Barbosa (1995), nos períodos quentes e de alta pluviosidade, comuns na primavera e verão, a contagem de larvas tende a diminuir, pelo efeito de lavagem, com o carreamento das mesmas da pastagem para o solo. Nesse período, há um exuberante crescimento vegetativo das pastagens, que dispersa mais facilmente as larvas, uma vez que é aumentada a matéria seca por área, aspecto que ocorreu intensamente no período experimental deste trabalho. Segundo os mesmos autores, o pico da contagem de OPG em ovinos ocorre nos meses de setembro e outubro, início de primavera, quando é relatado aumento das infecções por nematóides em rebanhos; a execução deste trabalho ocorreu em período posterior, ou seja, no verão e início do outono. Amarante et al. (1996) observaram baixo nível de contaminação das pastagens, no período de novembro a março.

Os movimentos das larvas no abandono da massa fecal são feitos em termos de migrações horizontais e verticais, por meio das quais podem alcançar a parte da vegetação que será ingerida pelo hospedeiro, e assim dar continuidade ao seu ciclo evolutivo (Castro et al., 2002). Provavelmente, o fato de a massa compacta de gramínea ter atingido altura superior a $50 \mathrm{~cm}$ prejudicou o contato do parasito com o hospedeiro, visto que as larvas migram horizontal e verticalmente pela pastagem até $40 \mathrm{~cm}$ do bolo fecal (Soulsby, 1965).

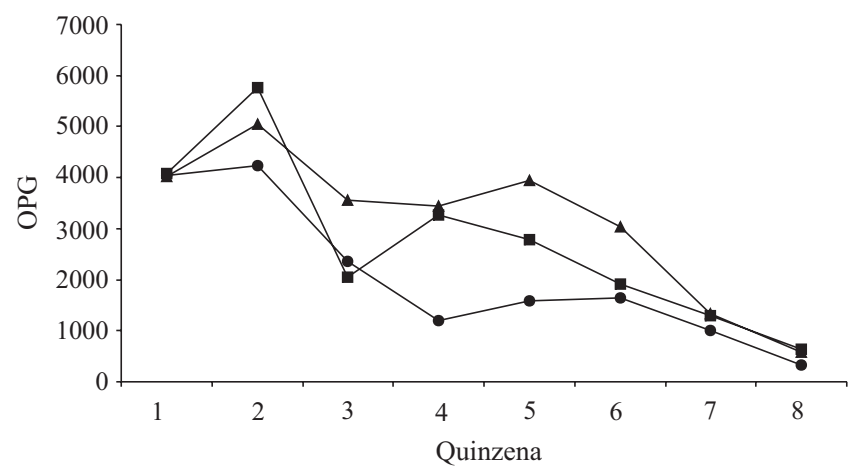

Figura 2. Valores médios, quinzenais, das contagens de ovos de tricostrongilídeos, por grama de fezes de ovinos dos grupos controle (๑), tratados com conídios, microencapsulados $(\boldsymbol{\Delta})$ e in natura ( $\boldsymbol{\square})$, de Arthrobotrys musiformis.
Na análise da migração vertical de larvas infectantes de nematóides gastrintestinais de ruminantes, Castro et al. (2002) observaram que as larvas do gênero Trichostrongylus foram recuperadas, em maior quantidade, nas porções medial e basal da gramínea, ao passo que Haemonchus foi encontrado, em maior quantidade, nas porções medial e apical.

Os resultados das coproculturas e da recuperação das larvas nas pastagens estão apresentados na Tabela 2. Os dados encontrados confirmam os resultados obtidos na necropsia dos animais traçadores (Tabela 3), ou seja, a prevalência dos gêneros Haemonchus e Trichostrongylus é maior que Oesophagostomum, visto que, esse último foi observado, na necropsia, apenas na forma histotrópica de nódulos, na mucosa do intestino grosso.

Resultados semelhantes foram encontrados por Amarante \& Barbosa (1995), em experimento realizado no Estado de São Paulo, ao longo de três anos, em que verificaram elevada freqüência de Haemonchus e Trichostrongylus.

Os resultados obtidos com os animais traçadores demonstram que o tratamento dos ovinos, tanto com conídios de A. musiformis microencapsulados quanto in natura, favoreceu a redução de T. colubriformis, tendo reduzido a taxa de infecção em 50,9\% e 57,6\%, respectivamente.

O grupo controle não apresentou formas adultas de $H$. contortus, fato que impossibilitou a avaliação do fungo nesse estágio parasitário. No entanto, um elevado número de L4 (2.170) foi observado, o que caracterizou, no tratamento com conídios in natura, uma redução de 95\%. O Haemonchus consolidou seu ciclo, passando pela fase histotrópica (L4) na mucosa do abomaso,

Tabela 2. Prevalência de larvas de helmintos dos gêneros Haemonchus, Trichostrongylus e Oesophagostomum, nas coproculturas realizadas com amostras fecais de ovinos e nas pastagens do experimento, no grupo controle, grupos tratados com conídios in natura e microencapsulados de Arthrobotys musiformis.

\begin{tabular}{lccc}
\hline Helmintos & \multicolumn{3}{c}{ Prevalência (\%) } \\
\cline { 2 - 4 } & Controle & In natura & Microencapsulado \\
\hline & \multicolumn{3}{c}{ Amostras fecais de ovinos } \\
Haemonchus spp. & 72 & 93 & 83 \\
Trichostrongylus spp. & 28 & 7 & 17 \\
Oesophagostomum spp. & 0 & 0 & 0 \\
\hline & \multicolumn{3}{c}{ Pastagens } \\
Haemonchus spp. & 51,4 & 60 & 56 \\
Trichostrongylus spp. & 37,1 & 40 & 36 \\
Oesophagostomum spp. & 11,4 & 0 & 8 \\
\hline
\end{tabular}


Tabela 3. Número e espécies de helmintos obtidos de animais traçadores colocados nos piquetes com ovinos dos grupos A (controle), B (conídios de Arthrobotrys musiformis microencapsulados) e C (conídios de Arthrobotrys musiformis in natura) e eficácia de controle.

\begin{tabular}{|c|c|c|c|c|c|c|}
\hline \multirow[t]{3}{*}{ Grupo } & \multicolumn{2}{|c|}{ Haemonchus contortus } & \multirow{3}{*}{$\begin{array}{c}\text { Trichostrongylus } \\
\text { colubriformis }\end{array}$} & \multicolumn{3}{|c|}{ Eficácia de controle $(\%)$} \\
\hline & \multirow[t]{2}{*}{ Adulto } & \multirow{2}{*}{$\mathrm{L} 4^{(1)}$} & & \multicolumn{2}{|c|}{ H. contortus } & \multirow[t]{2}{*}{ T. colubriformis } \\
\hline & & & & Adulto & $\mathrm{L} 4^{(1)}$ & \\
\hline \multirow[t]{2}{*}{ A } & 0 & 2.100 & 1.520 & \multirow{4}{*}{ - } & \multirow{4}{*}{-} & \multirow{4}{*}{-} \\
\hline & 0 & 2.240 & 4.310 & & & \\
\hline Total & 0 & 4.340 & 5.830 & & & \\
\hline Média & 0 & 2.170 & 2.915 & & & \\
\hline \multirow[t]{2}{*}{$\mathrm{B}$} & 20 & 3.180 & 1.450 & \multirow{4}{*}{0,0} & \multirow{4}{*}{26,5} & \multirow{4}{*}{50,9} \\
\hline & 1.440 & 10 & 1.410 & & & \\
\hline Total & 1.460 & 3.190 & 2.860 & & & \\
\hline Média & 730 & 1.595 & 1.430 & & & \\
\hline \multirow[t]{2}{*}{$\mathrm{C}$} & 7.700 & 120 & 2.420 & \multirow{4}{*}{0,0} & \multirow{4}{*}{95,0} & \multirow{4}{*}{57,6} \\
\hline & 1.030 & 100 & 50 & & & \\
\hline Total & 8.730 & 220 & 2.470 & & & \\
\hline Média & 4.365 & 110 & 1.235 & & & \\
\hline
\end{tabular}

${ }^{(1)}$ L4: forma imatura de $H$. contortus.

razão pela qual foi encontrada em todos os grupos experimentais.

Arthrobotrys musiformis mostrou-se promissor agente no biocontrole de nematóides parasitas, em virtude da capacidade de sobreviver após passagem pelo trato gastrintestinal e manter a ação predatória. Contudo, os resultados obtidos não são conclusivos. Há necessidade de se conduzir novos testes in vivo, para melhor equacionar e reduzir as adversidades encontradas, como condições ambientais, épocas estratégicas de aplicação e dosagens adequadas dos microrganismos a serem utilizados, assim como encontrar novas cepas e espécies de fungos eficientes no controle biológico de nematóides parasitos gastrintestinais de ovinos.

\section{Conclusões}

1. A passagem de Arthrobotrys musiformis pelo trato gastrintestinal dos ovinos, in vitro, não afeta sua capacidade em predar larvas de estrongilídeos.

2. Conídios de A. musiformis fornecidos aos ovinos, microencapsulados ou in natura, favorecem a redução de Trichostrongylus colubriformis, reduzindo a taxa de infecção dos animais; conídios fornecidos in natura atuam na redução das formas imaturas (L4) de Haemonchus contortus.

\section{Agradecimentos}

À Fundação de Amparo à Pesquisa do Estado de São Paulo (Fapesp), pela concessão da bolsa de doutorado ao primeiro autor.

\section{Referências}

AMARANTE, A.F.T.; BARBOSA, M.A. Seasonal variations in populations of infective larvae on pasture and nematode faecal egg output in sheep. Veterinária e Zootecnia, v.7, p.127-133, 1995.

AMARANTE, A.F.T.; PADOVANI, C.R.; BARBOSA, M.A. Contaminação da pastagem por larvas infectantes de nematódeos gastrintestinais parasitas de bovinos e ovinos em Botucatu, SP. Revista Brasileira de Parasitologia Veterinária, v.5, p.65-73, 1996.

ARAÚJO, J.V. Interação entre as larvas infectantes de Cooperia punctata e os fungos predadores do gênero Arthrobotrys, caracterização dos isolados de Arthrobotrys e seu uso no controle biológico de nematóides gastrintestinais de bovinos. 1996. 110p. Tese (Doutorado) - Universidade Federal de Minas Gerais, Belo Horizonte.

ARAÚJO, J.V.; GOMES, A.P.S.; GUIMARÃES, M.P. Biological control of bovine gastrointestinal nematode parasites in Southeastern Brazil by the nematode-trapping fungus Arthrobotrys robusta. Revista Brasileira de Parasitologia Veterinária, v.7, p.117-122, 1998. 
ARAÚJO, J.V.; GUIMARÃES, M.P.; CAMPOS, A.K.; SÁ, N.C. de; SARTI, P.; ASSIS, R.C.L. Control of bovine gastrointestinal nematode parasites using pellets of the nematode-trapping fungus Monacrosporium thaumasium. Ciência Rural, v.34, p.457-463, 2004.

ARAÚJO, J.V.; STEPHANO, M.A.; SAMPAIO, W.M. Passage of nematode-trapping fungi through the gastrointestinal tract of calves. Veterinarski Arhiv, v.69, p.69-78, 1999.

BANZATTO, D.A.; KRONKA, S.N. Experimentação agrícola. Jaboticabal: FUNEP, 1989. 247p.

BARRON, G.L. The nematode-destroying fungi. Ontario: Canadian Biological, 1977. 140p.

CASTRO, A.A.; ALMEIDA, L.R.; GUEDES JÚNIOR, D.S.; FARIA, M.F.R.; FONSECA, A.H. Migração vertical de larvas infectantes de nematóides gastrintestinais de ruminantes em pastagens, durante a estação chuvosa, no município de Seropédica, RJ, Brasil. In: CONGRESSO BRASILEIRO DE PARASITOLOGIA VETERINÁRIA, 12., 2002, Rio de Janeiro. Anais. Rio de Janeiro: Colégio Brasileiro de Parasitologia Veterinária, 2002. 1 CD-ROM.

CHANDRAWATHANI, P.; OMAR, J.; WALLER, P.J. The control of the free-living stages of Strongyloides papillosus by the nematophagous fungus, Arthrobotrys oligospora. Veterinary Parasitology, v.76, p.321-325, 1998.

COSTA, A.J. Diagnóstico laboratorial em parasitologia. Jaboticabal: Faculdade de Ciências Agrárias e Veterinárias - Unesp, 1982. 89p. Apostila.

FRAVEL, D.R.; MAROIS, J.J.; LUMSDEN, R.D.; CONNICK JUNIOR, W.J. Encapsulation of potential biocontrol agents in an alginate-clay matrix. Phytopathology, v.75, p.774-777, 1985.

GORDON, H.M.; WHITLOCK, H.V. A new technique for counting nematode eggs in sheep faeces. Journal of the Commonwealth Science and Industry Organization, v.12, p.50-52, 1939.
GRAMINHA, E.B.N.; COSTA, A.J.; OLIVEIRA, G.P.; MONTEIRO, A.C.; PALMEIRA, S.B.S. Biological control of sheep parasite nematodes by nematode-trapping fungi: in vitro activity and after passage through the gastrointestinal tract. World Journal of Microbiology and Biotechnology, v.21, p.717-722, 2005.

KEITH, R.K. Differentiation of infective larval of some common nematode parasites of cattle. Australian Journal of Zoology, v.1, p.223-235, 1953.

LARSEN, M.; WOLSTRUP, J.; HENRIKSEN, S.A.; DACKMAN, C.; GRØNVOLD, J.; NANSEN, P. In vitro stress selection of nematophagous fungi for biocontrol of parasitic nematodes in ruminants. Journal of Helminthology, v.65, p.193-200, 1991.

LEVINE, N.D. Nematode parasites of domestic animals and of man. Minneapolis: Burgess, 1968. 600p.

LITTLE, T.M.; HILLS, F.J. Agricultural experimentation designs and analysis. New York: Wiley, 1978. 350p.

MELO, A.C.F.L.; REIS, I.F.; BEVILAQUA, C.M.L.; VIEIRA, L. da S.; ECHEVARRIA, F.A.M.; MELO, L.M. Nematódeos resistentes a anti-helmíntico em rebanhos de ovinos e caprinos do Estado do Ceará, Brasil. Ciência Rural, v.33, p.339-344, 2003.

ROBERT, F.H.S.; O’SULLIVAN, P.J. Methods for egg counts and larval cultures for strongyles infecting tract of cattle. Australian Journal of Agricultural Research, v.1, p.99-102, 1950.

SAS INSTITUTE (Cary, Estados Unidos). User's guide: statistics. Cary, 1989-1996.

SOULSBY, E.J.J. Textbook of veterinary clinical parasitology. Oxford: Blackwell, 1965. 1120p.

SUSIN, I. Exigências nutricionais de ovinos e estratégias de alimentação. In: SILVA SOBRINHO, A.G. (Ed.). Nutrição de ovinos. Jaboticabal: FUNEP, 1996. p.119-141.

WALLER, P.J.; LARSEN, M.; FAEDO, M.; HENNESSY, D.R. The potential of nematophagous fungi to control the free-living stages of nematode parasites of sheep: in vitro and in vivo studies. Veterinary Parasitology, v.51, p.289-299, 1994.

Recebido em 18 de outubro de 2004 e aprovado em 2 de março de 2005 